\title{
Experiencias caóticas del descentramiento en la narrativa de Juan Francisco Ferré
}

\author{
Expêriencias caóticas do descentramiento nos romances de Juan Francisco Ferré
}

Chaotic experiences of moving-off in Juan Francisco Ferré's novels

Amélie Florenchie $\odot$

Université Bordeaux-Montaigne. Bordeaux, Francia.

\section{RESUMEN}

En varias de sus novelas, Juan Francisco Ferré cuestiona la decadencia española, enmarcándose en una tradición literaria que se remonta a la generación del 98. Según el escritor malagueño, España no consigue desembarazarse de una concepción de la modernidad fundada en la pareja imperialismo/colonialismo -herencia de la Ilustración europea-y particularmente problemática en un mundo globalizado. Sin embargo, los que intentan escapar de esta modernidad corrupta se ven abocados al fracaso como se ve en Providence (2008) y El rey del juego (2015). Aunque la narración se centra en protagonistas excéntricos dotados una mirada distanciada sobre su entorno, éstos no consiguen nunca llevar a cabo su empresa de descentramiento con respecto a su "metrópoli de nacimiento". En este artículo me propongo estudiar los motivos de este fallo e interrogar la visión crítica que Juan Francisco Ferré nos brinda de su país y de la globalización a través de ellas.

Palabras clave: Decadencia. Descentramiento. Imperialismo/Colonialismo. Nacionalismo. Identidad.

\section{RESUMO}

Juan Francisco Ferré questiona, em diversos romances, a decadência espanhola, afiliando-se a uma tradição literária que remonta à geração de 1998. Segundo o escritor originário de Málaga, a Espanha não consegue se livrar de uma concepção da modernidade fundada no par imperialismo/colonialismo, herança da ilustração europeia. Essa visão crítica é particularmente aguda em Providence (2008) e El rey del juego (2015) que oferecem experiências traumáticas de descentramento em relação à cultura e à identidade espanholas. Ainda que a narração se centre em protagonistas excêntricos que têm uma visão distante e distanciada do seu entorno, não conseguem levar à cabo sua empresa de descentramento da "metrópole de nascimento". Nesse artigo, proponho-me a estudar os motivos desse fracasso e a interrogar a visão crítica que Juan Francisco Ferré oferece de seu pais de origem e do contexto de globalização no qual está inserido.

Palavras-chave: Descentramento. Excentricidade. Decadência. Identidade. Globalização.

\section{ABSTRACT}

In his novels, the Spanish writer Juan Francisco Ferré points out the Spanish decadence, as did before him the Spanish writers of the Generación del 98. For Ferré, Spain is not able to throw away an obsolete conception of modernity, based upon the couple imperialism/colonialism, inheritance of the XVIII ${ }^{\text {th }}$ century. The reader can observe this very critical vision of Spain in Providence (2008) and El Rey del Juego (2015) which bring out two traumatic experiences of moving-off from the cultural and political center that is Spain. In spite of the fact that the two heroes are really eccentric, they don't manage to move away from their "home country". This paper aims to investigate the reasons why they both fail and analyze the critical point of view of Ferré on Spain inside the context of globalization.

Keywords: Decadence. Moving-off. Imperialism/Colonialism. Nationalism. Identity. 
En varias de sus novelas, Juan Francisco Ferré cuestrona la decadencia española, enmarcándose en una tradición literaria que se remonta a la generación del $98^{1}$. Según el escritor malagueño España sigue complaciéndose en su pasado dorado y no consigue desembarazarse de una concepción de la modernidad fundada en la pareja imperialismo/colonialismo, herencia de la Ilustración europea. En suma, España no habría logrado entrar de pleno en la modernidad. La diferencia de diagnóstico con la generación del 98 es la naturaleza del modelo de modernidad al que la península no lograría supuestamente conformarse: a finales del s. 19 se trataba de Europa, a principios del s. 21 , se trata de un modelo mucho más complejo de definir ya que no coincide necesariamente con unas fronteras geográficas; digamos que se trata de un modelo de civilización fuertemente inspirado en los EEUU, según un proceso de globamericanización por decirlo en palabras acuñadas por Fredric Jameson (JAMESON, 2009).

Esta visión crítica de una forma actual de la decadencia española es particularmente aguda en dos de sus novelas, Providence (2008) y El rey del juego (2015), desde dos perspectivas distintas, por no decir opuestas. Ambas novelas ofrecen casos de descentramientos, o más bien de tentativas, fallidas, de descentramiento con respecto a la cultura e identidad españolas. Aunque la narración se centra en protagonistas excéntricos que tienen una mirada distante y distanciada sobre su entorno, no consiguen nunca llevar a cabo su empresa de descentramiento con respecto a su "metrópoli de nacimiento". En Providence, el rechazo a España conduce al protagonista a ser letalmente absorbido par la fuerza centrípeta de su metrópoli de adopción: los EEUU. En El Rey del Juego, el rechazo a España lleva al protagonista a una experiencia ya no de descentramiento sino de desorientación y perdida de todos sus referentes. En este artículo me propongo estudiar los elementos claves de estas dos experiencias fallidas de descentramiento e interrogar la visión crítica que Juan Francisco Ferré nos brinda de su país y de la globalización a través de ellas.

En Providence (2008), Ferré cuenta las vicisitudes de Alex, cineasta español underground malogrado, quien aprovecha una oportunidad para instalarse en los EEUU e impartir clases sobre cine en la muy selecta Universidad de Brown. Allí se enorgullece de no caer en la caricatura del europeo que viene a los EEUU para dar una lección sobre lo que es la "verdadera" cultura: de ello se encarga un colega y compatriota suyo, encarnación a pesar suyo

\footnotetext{
Véase al respecto el apasionante ensayo de Javier Varela, La novela de España. Los intelectuales y el problema español, Madrid, Taurus, 1999.
}

de la decadencia del viejo imperio español ${ }^{2}$. Al contrario, Alex pretende ser capaz de descentrarse con respecto a su país de origen hasta fundirse en la cultura del otro. Sin embargo, muy rápidamente, el lector se da cuenta de que Alex no se integra tan fácilmente en el paisaje cultural estadounidense y que encarna, también a pesar suyo, otra forma de "cosmopolitismo del pobre" (SANTIAGO, 2012). En Providence, Alex descubre su condición de "emigrante cultural" en una metrópoli que acaba por machacarlo como mera carne de cañón en una guerra por mantener su imperialismo sobre el mundo.

Así es como es muy significativa su incomprensión recurrente con los habitantes de la zona, que se trate de sus colegas, de los estudiantes o de los anónimos con los que se cruza por la calle. Alex imputa esta incomprensión a la memez ajena mientras que no se da cuenta de que quien está totalmente desfasado con respecto a la realidad cultural norteamericana es él: sus referentes, pese a ser estadounidenses, no coinciden con los de los individuos que le rodean. No se da cuenta que han pasado por un filtro personal, genético, español que hace que cuando piensa en el cine de Spielberg, también piensa en el cine de Jess Franco, lo cual es poco probable que le ocurra en un cineasta norteamericano.

Además de esta incapacidad de comunicarse con los demás, basada en la ilusión de ser como "los otros", la novela ofrece una estructura que, como una trampa, poco a poco encierra al protagonista. Aunque ya tuve ocasión de estudiarla en un artículo anterior (FLORENCHIE, 2014), me gustaría recordar su funcionamiento en la medida en que se repite, en parte, en El Rey..

La estructura de la novela imita la de un videojuego sugiriendo que, al ir a vivir a los EEUU, Alex entra en un videojuego a escala humana sin darse cuenta de ello. La metáfora del videojuego es recurrente en el universo ferreano: símbolo de la cultura digital, es también símbolo de la digitalización de la realidad, un fenómeno que el escritor malagueño denuncia en su ensayo Mimesis y simulacro (FERRÉ, 2006, p. 11):

Cuando se ha consumado la digitalización de la realidad, es decir, el proceso de desrealización por el que la realidad se sitúa por entero bajo el signo y el imperio de lo virtual, ¿qué otra opción le queda a la narrativa, en este contexto de máxima inestabilidad de los referentes, excepto la de hacerse tan mediática y tecnológica como la realidad? Así, y solo así, podría hablarse de un realismo de alta definición, esto es, un realismo que tome plena conciencia del creciente dominio de lo artificial sobre todos los ámbitos de la realidad.

\footnotetext{
2 Del colega español, Alex dice que es un "paradigma del mal endémico de la cultura española" (p. 194), un "Balzac becado de por vida por el Estado de las Autonomías" (p. 195)
} 
La relación de Ferré a la cultura digital es bastante ambivalente en realidad: por un lado, la denuncia por sustituir lo virtual a lo real, pero por otro la fascina, de ahí su propuesta estética de "realismo full-HD". Esta misma ambivalencia le anima acerca de la globamericanización (2014, p. 125-149) $)^{3}$. De ahí la sorprendente ingenuidad de sus personajes: el profesor español caricaturesco de Brown que se enorgullece de encarnar la vieja Europa, y Alex también en la medida en que se cree capaz de abarcar nada menos que los EEUU. Providence es una parodia de novela de campus que poco a poco se convierte en novela de terror.

Volviendo a la estructura de la novela, revela cruelmente la ingenuidad del protagonista. La primera parte de la novela, titulada "El principio Delphine" (principio del fin) se parece a una "secuencia cinemática", en la que el usuario no puede interactuar todavía con el videojuego: Álex descubre en qué consiste su "misión" en Providence.

La transición de la secuencia cinemática al primer nivel del juego se hace mediante un epílogo titulado "Informe 1, PVD" que relata el violento episodio de la detención de Álex en el aeropuerto de Providence en el momento en que penetra pues sobre el territorio norteamericano: esta secuencia parece funcionar como una prueba iniciática en que Alex cambia de realidad.

La segunda parte de la novela, titulada "El movimiento browniano", en referencia a una teoría física sobre el movimiento aleatorio de las partículas de gran tamaño en un medio fluido provocado por el bombardeo de las moléculas del líquido, corresponde, pues, al primer nivel del videojuego: una vez en Providence, Álex cambia efectivamente de "realidad". Su trayectoria vital sigue un movimiento aleatorio en que sufre un bombardeo permanente de imágenes.

El paso del nivel 1 al nivel 2 del videojuego se hace mediante un segundo epílogo, titulado "Informe 2, PVD", que se concluye con un mensaje electrónico en forma de aviso al protagonista, como al lector: "En caso afirmativo, clica sobre el icono 'CTHULHU'. En caso negativo, clica sobre el icono 'P'. Si no pasas de pantalla, reinstala el programa inicial" (p.409).

La tercera parte, titulada "Conspiración Cthulhu", parece indicar que Álex ha optado por seguir jugando a Providence, bajo auspicios más que inquietantes como

\footnotetext{
3 En "Freakshow: la cultura americana en el espejo de la literatura", recopilado en America the beautiful: la presencia de Estados Unidos en la cultura española contemporánea, de José Manuel del Pino, Ferré señala: "el choque de un intelectual europeo o español con la cultura de masas norteamericana es, además de necesario, doblemente instructivo, por todo lo que revela sobre el otro cultural, desde luego, en forma de fantasías y fantasmas sobre otra vida posible de lo que en su día generó en su mismo seno cultural; pero también sobre sí mismo, sobre las razones de su debilidad creativa y los motivos de la decadencia de su influencia y poder en la escena mundial" (p. 130-131).
}

sugiere el nombre Cthulhu, uno de los más famosos monstruos creados por el escritor norteamericano H.P. Lovecraft, cuya característica es ser enemigo de cuanto existe...

Este segundo nivel le resulta demasiado difícil a Álex: su misión es un verdadero fracaso y, por tanto, muere.

La cuarta parte, titulada "Providence. Año uno", no corresponde a un "nivel" suplementario del juego, sino que constituye un epílogo en que se comenta la próxima puesta en venta de una versión mejorada del videojuego (p.577), como en un bonus-track.

Por otro lugar, la novela, de casi seiscientas páginas, se compone dentro de cada nivel de una gran cantidad de capítulos, muchos de ellos llamados "tomas" o "insertos", como si de un guion se tratase (antes de ir a Providence, le encargan a Alex un guion de cine). Sin embargo, su numeración sugiere varias elipsis y el texto resulta aparentemente incompleto, lo que confirma el narrador mismo en el capítulo titulado "Inserto 19. Exégesis", en que menciona tres finales posibles para la novela que "el infatuado Álex nunca contó" (p.526).

Vemos que Ferré desarrolla hasta sus últimas consecuencias las estrategias de control camuflado del texto por una instancia narrativa omnipotente, que puede permitirse decir al final, como en una atracción de feria, que: "ahora, todos abajo" (p. 587). Los lectores, como los personajes, parecemos meras fichas en este (video)juego literario.

La experiencia del videojuego a escala humana se repite en $E l$ Rey... aunque, al final de la novela, el protagonista no muere; al contrario, hasta le invitan a disfrutar del videojuego creado a partir de su experiencia. Es decir que, desde Providence hasta El Rey..., el protagonista ferreano ha conseguido superar la prueba de la virtualización de la realidad y al formar parte del sistema, tiene la posibilidad de empezar a subvertirlo. Pero antes de intentarlo, ha tenido que sufrir esa prueba traumática de la digitalización de la realidad y, con ella, otra experiencia fallida de descentramiento en su propio país.

Lo que me propongo ahora es centrarme en esta segunda novela que no ha sido estudiada hasta hoy, al menos que yo sepa, y que se enmarca en la reflexión que Ferré, como otros escritores de su generación (me estoy refiriendo a escritores tan distintos entre ellos como Manuel Vilas o Enrique Vila-Matas), lleva a cabo sobre la problemática identidad española en un mundo globamericanizado.

En esta novela, el escritor malagueño pone de realce el desfase entre el mantenimiento de cierto imperialismo cultural por parte de las élites españolas en un mundo 
en que España se ha convertido en una colonia muy periférica. El novelista plantea desde las primeras líneas del texto, la ya antigua irrelevancia de España en el escenario internacional a raíz de la celebración del centenario del principio de la primera guerra mundial en 2014: "la celebración del primer centenario de una guerra mundial en la que no participamos" (p.13).

A través de una serie de dispositivos retóricos, Ferré desmonta uno a uno los mecanismos del seudoimperialismo español y muestra la imposibilidad para el protagonista de tomar distancia y tener una perspectiva en un país que ha perdido su profundidad. Ferré no solo cuestiona la identidad española actual, sino que también cuestiona la historia de la literatura de su país y reinventa o, al menos, renueva, la perspectiva de la generación del 98 sobre España, como vamos a ver.

La novela cuenta las peripecias de $\mathrm{Axel}^{4}$ por una España desconocida. El "juego" consiste esta vez en salvar al Rey de España de una tentativa de asesinato por parte de un grupo terrorista desconocido con la ayuda de dos agentes secretos. Durante su misión, el trio de hombres no solo no encuentra al Rey, sino que matan a uno de sus dobles y los dos agentes secretos pierden la vida en ello. Además, esta excursión por la España rural, auténtica, profunda (el videojuego inspirado en la misión de Axel se llama al final de la novela "España profunda"), no lleva a los personajes a más de cincuenta kilómetros de Madrid. Como en una pantalla de ordenador, no consiguen superar la bidimensionalidad de la realidad y acaban presos de una carretera en forma de cinta de Moebius.

A partir del capítulo XVII (la novela cuenta con dos partes de XL capítulos cada una), se encuentran atrapados en una Castilla simulacral, presos de una alucinación colectiva en la que aparecen, uno tras otro, los mitos fundadores de España en pleno proceso de descomposición y entre ellos, el Quijote. Los personajes recorren el país en busca ya no de los molinos/gigantes sino del Rey y de sus dobles, como en una reescritura paródica de la obra de Cervantes. Además de la intriga, la estructuración de la novela emula de manera transparente la del texto cervantino: dos partes (como las dos salidas del caballero andante), ambas constituidas de varios capítulos, con números romanos, pero sin títulos, que cuentan las distintas "aventuras" de los personajes. También se acumulan manidas alusiones al texto cervantino, como la mención del narrador a una lectora de cuyo nombre Axel pretende no querer acordarse (p.21), o el sintagma "camarero de la triste figura" para designar al camarero de un bar cutre de Madrid (p.32), o el eco al famosísimo capítulo de los molinos (p. 150:

\footnotetext{
4 Axel es un doble transparente del Alex de Providence, aunque es escritor y exitoso. En el momento en que empieza la novela, atraviesa una crisis personal profunda.
}

"Ya verás como la pastilla [de droga] te hace ver viejos molinos donde solo hay gigantes agazapados"), y otras por el estilo: "Willy arribó a sus vigilados dominios, con sus maneras de caballero andante" (p. 155), "mis queridas hijas, ya podéis marcharos y dejarme a solas, por favor, con los tres beduinos de la Sierra Morena" (p. 162), "La historia del cautivo de Casablanca" (p. 176), "la graciosa gitanilla" (p.232), etc.

La perezosa reescritura del texto cervantino y su permanente contigüidad con otros referentes sacados de la cultura de masas (el personaje recurrente de la "famosa" Cristina Pedroche, transformada en Cristina Peluche, el bollycao, etc.) ilustra la debilitación de la "alta" cultura española. Según Ferré, no es la consecuencia directa de la globamericanización contrariamente a lo que se podría pensar, sino más bien de un proceso de mercantilización de la cultura iniciado hace varias décadas. El escritor malagueño denuncia la aplicación de las sucesivas políticas culturales neoliberales llevadas a cabo en España, especialmente a partir de los años noventa. Recordará quizás el lector que, al ser nombrada Ministra de Educación y Cultura en 1996, en el primer gobierno de José María Aznar, Esperanza Aguirre pronunció un discurso ante la Asamblea en que legitimó la mercantilización de la cultura al comparar los libros con los zapatos para justificar la desregulación de su precio: "Los libros son como los zapatos. ¿A quién se le ocurriría controlar el precio de los zapatos...?"5. Según Ferré, esta mercantilización ha sido posible a causa de una concepción de la cultura española heredada del franquismo.

Lo que hoy se llama "marca España" no es sino la versión actualizada del "Spain is different" forjado por los tecnócratas franquistas de los años sesenta. Según Ferré, estos lemas destinados en un primer tiempo a los turistas se han convertido rápidamente en realidades para los españoles mismos, debido al "páramo cultural" que es España desde el franquismo. Como ha mostrado Juan Pablo Fusi, el clima cultural del régimen de Franco "quedó definido mucho más por la subcultura de consumo de masas que por la propia cultura oficial" (FUSI, 1998, p. 109), por la sencilla razón de que una subcultura ajena a preocupaciones políticas e intelectuales, de gran popularidad y difusión pública, favorecía la integración social y la desmovilización del país a través del entretenimiento y la evasión. De modo que desde hace más de cincuenta años, se ha ido imponiendo a los españoles una identidad fabricada, como si fueran turistas en su propio país; una identidad generada a partir de una

\footnotetext{
5 Ver Ana Nuño, "La feria de las vanidades: crítica literaria y mercado en la España post-posmoderna”, en Intransiciones. Crítica de la cultura española, ed. Eduardo Subirats, Madrid, Biblioteca Nueva, 2002 p. 87-101.
} 
serie de "postales emocionales", según la expresión de Elena Delgado (2015, p. 199); una identidad superficial.

En particular, la novela pone en escena la ridiculez de los afanes imperialistas de una España que está dando sus últimos coletazos a través de la crisis monárquica que sacudió el país en los últimos años y condujo a Juan Carlos I de España a abdicar a favor de su hijo, Felipe VI, en junio de 2014 tras una serie de escándalos que involucraban directamente al rey o a miembros de su familia (corrupción, safari en Botsuana, etc.). Toda la novela gira en torno al fallido y falso rescate del rey de España, como ya he dicho. Los protagonistas resultan incapaces de identificar al "verdadero" rey entre sus numerosos "dobles", destinados a sustituirlo en casos de extrema urgencia pero también resulta que la amenaza que pesa sobre el Rey es un simulacro, una manipulación orquestada por el poder mismo para intentar salvar su popularidad en caída libre. La vacancia del poder real (con el doble sentido de la palabra en español) no puede ser más explícita. Lo que señala la novela es también la razón de esta vacancia: el carácter obsoleto del poder real, es decir monárquico en este caso. Para Ferré resulta claro que la monarquía española no tiene ya razón de ser en un país que, por otra parte, pretende tener un régimen democrático basado pues en una democracia constitucional y parlamentaria.

Además, Ferré recuerda a los lectores de El Rey... el incidente diplomático sucedido a raíz de la Cumbre Iberoamericana de 2007, durante un encuentro oficial entre jefes de estado, cuando el entonces rey Juan Carlos I le dijo al entonces Presidente de Venezuela, Hugo Chávez: "Por qué no te callas". Aunque fue una innegable falta de respeto por parte del más alto representante de España hacia el más alto representante de Venezuela, con resabios racistas, es bueno recordar que este incidente, en vez de hundir la reputación del rey en España, la incrementó considerablemente, consolidando un nacionalismo con sabor a neocolonialismo muy del gusto de los nostálgicos sin saberlo del franquismo (se vendió en España una multitud de productos derivados de este incidente como melodías de timbre para móvil, etc.). Y el rey nunca le presentó disculpas a Chávez. No obstante, para que el lector no olvide la indecorosa frase, el narrador ferreano la pone en boca de los odiosos agentes secretos, con variaciones mínimas pero que recalcan cada vez más

\footnotetext{
6 La figura del doble, asociada con la idea de simulacro, es decir, de copia de un objeto cuyo original ha desaparecido, se declina a través de varios personajes: desde los agentes secretos, hermanos gemelos, llamados Danny (Daniel) y Willy (Guillermo), ellos mismos dobles de los hermanos Wachowski gemelos y transgéneros; el personaje de Marta Sánchez/Cristina Pedroche, que resulta ser un ciborg, hasta la pareja del viejo inválido y la enana, trasuntos lynchianos, todos ellos funcionan como el doble el uno del otro.
}

su carácter insultante: "Por qué no te callas de una vez, tío" (p.45), "Tío, por qué no te callas" (p. 72), "Cállate, gilipollas" (p.93), "Y tu cállate un poco, McClane" (p.101), "Cállate un poco, y déjame pensar" (p.142), "Cállate, McClane”, (p. 154), "Cállate, mierda, ¿es que no me has oído? ¿Que te calles, coño!” (p.156), "A ver si calla la bocaza de una puta vez" (p. 176), “[...] cállate para siempre" (p. 196).

Esta desafección por la Corona española se debe a una visión de la historia reciente de España que vincula el régimen monárquico con el régimen franquista. Ferré forma parte de una generación de intelectuales, entre ellos muchos historiadores, que llevan ya una década deconstruyendo "el gran mito de la Democracia española" (DELGADO, 2015, p.106), mito que imperó hasta finales del siglo XX y se desmoronó completamente con los atentados del $11 \mathrm{M}$ y la mentira del entonces jefe de gobierno, José María Aznar, sobre la identidad de los terroristas. La revisión de la Transición que proponen descansa sobre un hecho incuestionable: el rey Juan Carlos había sido designado como sucesor por Franco mismo y la monarquía, aunque fuera constitucional y parlamentaria, había sido decidida como tal por el dictador. Afirmar una continuidad entre la España franquista y la España posfranquista, es decir democrática, supone la supervivencia de la "ideología" franquista en la sociedad española actual bajo la forma de un sentimiento nacional basado en un sustrato imperial/colonial heredado del franquismo. El "nacionalcatolicismo" se apoyaba en una visión reaccionaria de la nación española como se sabe, basada en una reescritura gloriosa de la historia de España, poniendo énfasis en la Reconquista, en el reinado de Isabel y Fernando, les reyes católicos, y en la Conquista de América; el imperio colonial español era pues un elemento fundamental del nacionalismo español.

Este sentimiento nacionalista reaccionario encuentra en la novela de Ferré otro terreno abonado a través del tratamiento de la cuestión del futbol. Como dije antes, la acción sucede durante el verano de 2014, "verano mágico de la debacle futbolística del país" (p. 16). El motivo de la debacle futbolística reaparece en varios momentos del texto, formando una antiepopeya nacional tal una reescritura paródica del Poema de mío Cid.

En los fragmentos XX a XXIII de la novela, se relata la "aventura" del trío infernal en un bar de carretera llamado "El Pibe": es, como se sabe, el apodo que se les dio a varios futbolistas procedentes de América Latina (Carlos Valderrama, el colombiano, y, sobre todo, Diego Maradonna, apodado "el pibe de oro") y es el segundo establecimiento del que es cuestión en la novela, llamándose el primero "de Bringas", en clara alusión a la novela epónima de Galdós. De allí que se dibuja una 
clara oposición entre por un lado los españoles y por otro los latinoamericanos en su conjunto.

Tras acomodarse en la barra, los tres protagonistas se dan cuenta de que los clientes y el dueño del local, argentinos, están viendo un partido del Mundial de fútbol, del que la selección española, la "rojigualda", ha quedado eliminada tras una competición malísima. En un momento dado, uno de los agentes secretos le pide al dueño que apague el televisor y con su actitud irrespetuosa hacia los argentinos desata una refriega. Inesperadamente, se llega a un consenso ya que ninguno de los dos bandos quiere que intervenga la policía sin que se sepa muy bien por qué, pero este consenso aparece como un acuerdo hipócrita: "El consenso se huele a distancia. Es como el aliento de un alcohólico, como un perfume caro en una piel de seda o como los efluvios de un cadáver, algo que se inhala a fondo y termina entrando a formar parte de tus células más íntimas. Hasta el punto de que ya no sabes cómo comportarte cuando no existe o no lo sientes con intensidad suficiente" (p. 74).

La tensión es palpable y aunque haya vuelto "la paz", el mismo agente secreto que había provocado el enfrentamiento no puede evitar soltar un discurso racista en dirección de sus adversarios 7: "Todos nosotros, me oís bien, todas estas gentes estaban aquí mucho antes de que vosotros llegarais devolviéndonos la visita de cortesía [la Conquista]. Así que un respeto por favor. Este país lleva la derrota en la sangre y la victoria en los huevos. En la historia, vamos primero. En el fútbol igual, ¿qué os habéis creído?" (p.76).

Lo que aparece al principio como una mera rivalidad futbolística entre España y Argentina revela restos de un imperialismo/colonialismo español mal digeridos. Además, la visión negativa del consenso que se destaca de la cita anterior parece condenarlo como fórmula política engañosa, lo cual no es anodino en un país cuya transición de la dictadura a la democracia está supuestamente basada en un consenso. Según sostiene Chantal Mouffe en L'illusion du consensus (2016), el consenso no es sino la expresión de un pensamiento hegemónico, lo cual implica que la democracia no es sino un régimen opresor. De ese modo, la crítica de Ferré al consenso es una crítica más global a la España de la Transición democrática, vista como el paradigma del consenso político y por lo tanto como democradura (MOUFFE \& LACLAU, 2009).

El hecho de que esta crítica radical pase por el fútbol en la novela no es anecdótico. Los vínculos entre Estado y deporte en España y, en especial el fútbol, no son nuevos; han sido analizados brillantemente por Manuel

\footnotetext{
7 En Providence, ya ocurría un incidente de este tipo entre Alex y una de sus estudiantes, argentina por cierto. Quizás sea necesario recordar aquí que, además, los argentinos tienen fama de presumidos en el mundo hispánico.
}

Vázquez Montalbán, sin olvidar el genial concepto de "nacionalfutbolismo" forjado por David Gómez. También, en La nación singular, Elena Delgado analiza la dimensión simbólica de la victoria de la selección española en el Mundial de fútbol de 2010 y su papel en la consolidación de un sentimiento nacionalista español muy centralista y muy (neo)imperalista/colonial. Según la ensayista, la victoria de la rojigualda fue objeto de una manipulación política al convertirse en victoria simbólica de la unidad nacional cuando en realidad la selección es plural y más aún en un país regido por un sistema de autonomías (jugadores procedentes de Castilla, Asturias, Cataluña, etc.). ${ }^{8}$ Además, Delgado se admira de que cuando la Roja ganó la semifinal contra Alemania y la final contra Holanda, la prensa holandesa denunciara constantemente la "Furia Roja" (la brutalidad de los tercios de Flandes dejó una marca profunda en la memoria colectiva del país) mientras que la prensa española se alegrara de que, por fin, España se hubiera deshecho de sus viejos demonios respecto a las potencias del Norte. Volvía pues el fantasma de la famosa "leyenda negra" de España, basada en ataques personales al rey Felipe II, la denuncia de la intolerancia religiosa simbolizada por la Inquisición, y la denuncia de la masacre de los pueblos indígenas de América, y fomentada desde Holanda por Guillermo de Orange-Nassau para luchar contra el imperialismo español, tan fuerte a finales del s. XVI ${ }^{9}$. Si, a juicio de Delgado, ese brote nacionalista no era sino un producto mediático efímero ${ }^{10}$, me parece al contrario muy revelador de la persistencia de valores imperialistas/ coloniales en España, con respecto tanto a su pasado como a su funcionamiento interno: desempeñando Madrid y Castilla el papel de metrópoli y el resto del país, el papel de periferia "colonizada" 11 . Lo cual explica también la reacción -ficticia, por cierto- tan negativa de los personajes ferreanos cuando en 2014 la rojigualda es rápidamente eliminada del Mundial.

Estos distintos elementos traducen la dificultad de definir la identidad española. Al principio de su viaje por España, al protagonista de El Rey... le preguntan con insistencia si “está seguro de ser español” (p.48-50), como

\footnotetext{
8 Remito al lector a las portadas del "ABC", a las crónicas de Ignacio Camacho y a la actitud siempre despectiva de Sergio Ramos, andaluz, hacia los periodistas catalanes que se dirigían a Piqué o Puyol en catalán para hacerles preguntas, como bien recuerda Elena Delgado en su libro citado.

9 Ver Joseph Pérez, La légende noire de l'Espagne, París, Fayard, 2009, p. 83-146.

${ }^{10}$ Elena Delgado recuerda que poco después de las celebraciones se volvió a asociar la bandera española con la derecha y los conservadores (op. cit., p. 229).

${ }^{11}$ Este imperialismo se manifiesta a nivel político con un estado de las autonomías que en la actualidad no logra encontrar su razón de ser entre federalismo y centralismo como revela la crisis catalana que, en 2015 , cuando se publicó el libro, no había alcanzado todavía su paroxismo.
} 
si aquello no tuviera sentido. Difícil, así mismo, definir España, como intenta hacerlo sin embargo uno de los personajes: "España es todo en un solo ente: monarquía y república, aristocracia y anarquía, modernidad y arcaísmo, fealdad y belleza, orden y caos, catolicismo y paganismo, socialismo y fascismo, revolución y derecho constitucional, picaresca y quijotismo, elegancia y esperpento. Todo en una. España profunda y España superficial. ¿A que suena bonito como campaña publicitaria de la marca España en el extranjero?" (p. 171-172) ${ }^{12}$. Al final de la novela, los protagonistas no han avanzado un ápice en su búsqueda de la esencia española: "España [es] un país viejo y lleno de gente muy vieja, viejos valores, viejas mitologías, no pretendas cambiar las cosas de un día para otro. [...] Y el resto es pura apariencia. Embelecos para turistas y gacetilleros" (p.258).

En La nación singular Elena Delgado se interroga sobre la viabilidad de una identidad nacional fabricada por el Estado y estrechamente vinculada con la cultura política del consenso que se desarrolló a raíz de la transición democrática. El propósito de Delgado no es el mío aquí, ya que se sitúa ella en una perspectiva de reflexión sobre el nacionalismo catalán. Sin embargo, es interesante retener la idea de que la Transición democrática no constituyó una ruptura en la construcción de la identidad y la cultura españolas sino más bien una continuidad con el franquismo. En Intransiciones, es decir antes de que se empezara a criticar la llamada "CT" (Cultura de la Transición, término acunado por Guillem Martínez ${ }^{13}$ ), Eduardo Subirats señalaba ya la continuidad entre la dictadura de Franco y la democracia española, acusando al Estado español de ceguera por adaptarse al molde de una democracia (neo)liberal, fruto del capitalismo tardío, sin cuestionarlo (Subirats, 2002: 12). En este sentido, Ferré considera la globamericanización de España no tanto como la consecuencia del imperialismo estadounidense sino como la consecuencia de "valores" del franquismo persistentes en la sociedad española. Algo podrido hay en el reino de Dinamarca...

Me parece interesante abordar ahora un último elemento de la novela de Ferré que indaga, a pesar de

\footnotetext{
${ }^{12}$ La cita completa es la siguiente: "España se ha salido en muchas ocasiones del eje de la historia. Unas para perderse en caminos sin salida, atolladeros que parecían atajos y solo conducían al desastre. Otras veces, España ha entrado en bucles con sus propias esencias, trazando círculos viciosos que esterilizaban su fuerza. Hay muchas Españas conviviendo bajo la apariencia de una unidad que no ha existido nunca más que en el cerebro de algunos gerifaltes. Españas anómalas, simultáneas, asimétricas, Españas estancas. Llámelas como quiera. Ahora mismo está en una de sus versiones. Cuando salga de parranda con sus amigotes estará en otra muy distinta. A veces se producen intersecciones negativas. Pero lo más frecuente es un discurrir paralelo. Ya la guerra siempre en el trasfondo como solución provisional a los problemas de ajuste" (p. 171)

13 Guillem Martínez (ed.), CT o la cultura de la Transición, Madrid, Ediciones Debolsillo, 2012.
}

todo, en un posible descentramiento desde la literatura. Como ya hemos dicho, la novela cuenta la manera como, sin saberlo, Alex participa en un videojuego a escala humana y logra salvar el pellejo al contrario de su doble novelesco de Providence, Alex. La novela se cierra sobre una invitación a jugar: "La orden terminante del círculo vicioso había sido emitida hacia demasiado tiempo como para rechazarla con evasivas. Y así nos lo anunciaban los extraños caracteres de diseño futurista bailoteando en la pantalla blanca al ritmo programado de una música machacona. Play" (p. 276). Esta invitación al juego responde también a la cita puesta en epígrafe del texto, sacada de uno de los diálogos de Juan Luis Vives titulado precisamente "El juego de naipes": "Al triunfo de España, y el que dé los naipes retendrá la muestra aunque sea as o figura humana".

Por lo tanto, la macroestructura de la novela no corresponde a un videojuego sino a una partida de cartas. La portada de la novela reproduce en efecto un juego de naipes español del s. XVI como se indica en los créditos, y la novela se divide en dos partes de XL fragmentos cada una, separadas por la reproducción de una baraja española (afrancesada, ya que lleva dieces), y tituladas respectivamente "Las cartas y los jugadores" y "La gran partida". Esto sugiere finalmente que el verdadero hipotexto de $E l R e y . .$. no es el videojuego ficticio "España profunda", ni el Quijote sino el diálogo de Vives, "El juego de naipes". Este diálogo forma parte de un conjunto destinado al príncipe Felipe, hijo de Carlos $\mathrm{V}$ y, más adelante, debido a su éxito, a un público de lectores juveniles para amenizar su aprendizaje del latín adaptándolo a su entorno inmediato (originalmente se publicaron en latín). Vives, reconocido pedágogo, recoge pues momentos de la vida diaria de los españoles del s.XVI como el juego de naipes, la salida de la escuela y los expresa en latín, para convencer -ya en aquella época- que el latín es una lengua moderna. Con el tiempo, estos ejercicios se convirtieron en verdaderas escenas de costumbres con imprescindible valor documental ${ }^{14}$. El hecho de que Ferré remita a este texto nos lleva a plantear de nuevo la cuestión del descentramiento y con ella la de la identidad de España en un mundo globamericanizado. Creo que hay que entender la novela de Ferré como una apuesta (un juego) por el renacimiento español: de ahí la idea de referirse a un escritor del Renacimiento, más que del Siglo de Oro, de ahí también la selección de la cita (se trata de apostar por el triunfo de España). Sin caer en

\footnotetext{
14 "Del interés que pudieran tener los diálogos de Vives como libro didáctico se ha pasado a considerarlo como libro costumbrista, como vademecum de la vida diaria de la Europa de 1537', en Carmen Bravo Villasante, Los "Diálogos escolares" de Juan Luis Vives, 1616. Anuario de la Sociedad Española de Literatura General y Comparada, Vol. V (Año 1983-84), p. 7-11. URL: http://www.cervantesvirtual.com/nd/ark:/59851/bmc5t3z6
} 
otra forma de nostalgia imperialista, lo que propone Ferré es dar un paso de lado, descentrarse levemente y volver a descubrir la España de Vives: no la del tan imperialista Carlos V, pero la de la España de tradición humanista encarnada por un escritor español converso y que pasó gran parte de su vida fuera de España por miedo a la Inquisición, codeándose con nadie menos que Erasmo, Tomas Moro, y los "grandes" de aquel mundo. A través de este epígrafe, Ferré nos invita pues a apostar por el "triunfo" de las humanidades en un mundo digitalizado desde la distancia que confiere el juego, en este caso un juego literario.

\section{Referencias}

BRAVO VILLASANTE, Carmen. Los Diálogos escolares de Juan Luis Vives, 1616. Anuario de la Sociedad Española de Literatura General y Comparada, Vol. V (Año 1983-84). p. 7-11.

DELGADO, Elena. La nación singular. Madrid: Siglo XXI de España editores, 2015.

FERRE, Juan Francisco. Mimesis y simulacro. Málaga: e.d.a libros, 2011.

FERRE, Juan Francisco. Freakshow: la cultura americana en el espejo de la literatura. En: DEL PINO, J. M. (ed.). America the beautiful: la presencia de Estados Unidos en la cultura española contemporánea. Madrid: Iberoamericana/Vervuert, 2014. p. 125-150. https://doi.org/10.31819/9783954872619-008

FLORENCHIE, Amélie. El realismo full-HD de Juan Francisco Ferré. Pasavento: Realidad virtual y cibercultura, [S. l.], v. I, n. 2, p. 265-281, verano 2013.

FUSI, Juan Pablo. Un siglo de España. La cultura. Madrid: Marcial Pons, 1998.

JAMESON, Fredric. Valences of dialectic. Londres/Boston: Verso, 2009.

MARTINEZ, Guillem. CT o la cultura de la Transición. Madrid: Ediciones Debolsillo, 2012.

MOUFFE, Chantal. L'illusion du consensus. 2016.

MOUFFE, Chantal; LACLAU, Ernesto. L'itinéraire de la démocratie radicale. Raisons politiques, [S. l.], v. 3, n. 35, p. 207-220, 2009. https://doi.org/10.3917/rai.035.0207

NUÑO, Ana. La feria de las vanidades: crítica literaria y mercado en la España post-posmoderna. En: SUBIRATS, Eduardo (ed.). Intransiciones: crítica de la cultura española. Madrid: Biblioteca Nueva, 2002. https://doi.org/10.1515/iber. 2004.144

SANTIAGO, Silvano. El cosmopolitismo del pobre. Cuadernos de Literatura, Bogotá, n. 32, jul.-dic. 2012, p. 309-325.
SUBIRATS, Eduardo. Introducción. En: SUBIRATS, E. (ed.). Intransiciones: crítica de la cultura española, Madrid, Biblioteca Nueva, 2002. https://doi.org/10.1515/iber.2004.144

VARELA, Javier. La novela de España: los intelectuales y el problema español. Madrid: Taurus, 1999.

Recibido en: 12/2/2019.

Aprobado en: 29/10/2019.

Publicado en: 21/12/2019.

Autora:

AmÉlie FloRENCHIE

Doctor, Profesor de conferencias-HDR, Université Bordeaux-Montaigne, Bordeaux, Francia.

Orcid: http://orcid.org/0000-0001-6844-2401

E-mail: aflorenchie@gmail.com

Dirección: Domaine Universitaire, 19 esplanade des Antilles

33607 Pessac, Francia 